\title{
DIFICULDADES DE INTEGRAÇĀO À UNIVERSIDADE SENTIDAS PELOS ESTUDANTES DO CICLO PRÉ-PROFISSIONAL
}

\author{
Suely de Souza Baptista*
}

RESUMO - Durante o ciclo pré-profissional do curso de enfermagem vem ocorrendo um
crescente número de matrículas trancadas, reprovações e transferências. Além do apro-
veitamento deficiente dos alunos, nota-se uma carga horária semanal excessiva, dificul-
dade de adaptação aos modelos pedagógicos da Escola Ana Neri e do Centro de Ciências
da Saúde e até discriminação social. Este estudo consiste em uma pesquisa quanti-
-qualitativa e se propõe a analisar o perfil e as percepçóes para a problemática encontrada.

\begin{abstract}
During the pre-professional phase of the Nursing course has been occurring an increase of canceled enrollments, reproofs and transferences. Besides the deficient performance of the students, it is noted an excess of hours in the weekly schedule, making difficult the adaptation to the pedagogic models at school Ana Neri and Center of health Sciences, and even social discriminatio. This study consists on a quantitative-qualitative research and it proposes to analyse the profile and the perceptions of the student and to discuss alternatives of solution to thes problem.
\end{abstract}

\section{INTRODUÇĀO}

A Escola de Enfermagem Ana Neri da Universidade Federal do Rio de Janeiro (UFRJ), a partir do 2. semestre de 1978 passou a implantar um nova abordagem curricular em seu Curso de Graduação. Essa reformulação trouxe como mudança a ampliação das experiências de aprendizagem no que se refere ao continuum saúde-doença, e como estratégia correspondente, a substituição das primeiras experiências práticas, que se davam anteriormente no cenário hospitalar, por outras junto a grupos, mais ou menos homogêneos, em situaçōes de estudo e/ou trabalho. Os três primeiros programas curriculares interdepartamentais, que formam a Primeira Etapa do Currículo de Enfermagem desenvolvem-se paralelamente às disciplinas comuns às carreiras da Saúde, durante os três primeiros períodos do Ciclo Pré-Prof issional. A idéia norteadora dessa nova concepção curricular é a integração, entendida das seguintes formas: integração da teoria à prática, em que o conhecimento teórico e a experiência estão dialeticamente associados, de tal forma que um, permita a consolidação do outro; a integração estudo-trabalho, em que os estudantes, ao participarem nos campos de estágio das equipes de campos de estágio das equipes de saúde, desenvolvem atividades produtivas na Instituição e contribuem para a melhoria do nivel de saúde da coletividade; e a integração disciplinar, em que o processo ensino-aprendizagem se realiza em torno de experiências significativas para o alcance de competências, para o que todas as disciplinas a elas relacionadas dão sua contribuição.
Esta nova proposta curricular favorece o encontro do professor de enfermagem com o estudante, imediatamente apos seu ingresso na Universidade e em condiçōes que permitem um conhecimento mais aprofundado destes estudantes. Provavelmente devido a isto também, atualmente as professoras vêm identificando uma série de dificuldades enfrentadas pelos estudantes durante o Ciclo Pré-Profissional. As dificuldades expressadas por eles dizem respeito principalmente a:

- excesso de horas/aula, o que impede um bom aproveitamento, pois não há tempo disponível para o estudo dos temas ministrados;

- discriminação dos estudantes de enfermagem por alguns professores do Ciclo Pré-Profissional e por estudantes de outras áres;

- inadequação dos conteúdos teóricos às competências previstas para o aluno ao término do Ciclo Pré-Profissional.

- quantidade e/ou complexidade excessiva da matéria dada;

- insuficiência e/ou inadequação dos estudos secundários, apesar da aprovação no vestibular;

- discrepância entre a metodologia de ensino do currículo de enfermagem e das disciplinas do Ciclo Pré-Profissional.

Os fatos de que um crescente número de estu-

\footnotetext{
* Professor Adjunto da Escola de enfermagem Ana Neri/UFRJ

Bolsista do CNPq - Categoria Pesquisa.
} 
dantes não comparecem para matricular-se, são reprovados, trancam matrícula ou pedem transferência, são desconcertantes para a Escola de Enfermćgem, que se propōe a of erecer o melhor ensino possível. Porém, pouco conhecemos a respeito de como os estudantes vivenciam essas situações.

$O$ presente estudo consiste numa primeira abordagem do problema mediante a análise das facilidades e dificuldades que se of erecem aos estudantes durante o Ciclo Pré-Profissional; da comparação entre as expectativas e as experiências das prof essoras do Curso de Enfermagem no que se refere ao Ciclo Pré-Prof issional e a discussão das alternativas de encaminhamento para a situação encontrada.

Este estudo baseia-se em documentos da Coordenação do Curso de Graduação da Escola de Enfermagem Ana Neri e nos depoimentos de professoras e estudantes da Escola. As professoras deram depoimentos acerca das recordações de suas experiências no período em que foi implantada a Reforma Universitária na Universidade Federal do Rio de Janeiro e suas opiniōes sobre o resultado dessa Reforma para o ensino da enfermagem. Os estudantes de enfermagem nos falaram sobre suas experiências de vida familiar e suas vivências nas atividades curriculares do curso de enfermagem e junto aos outros estudantes da área da saúde.

\section{ANTECEDENTES DA REFORMA UNIVER- SITARIA E SUAS CONSEQÜÊNCIAS PARA O ENSINO DA ENFERMAGEM NA ESCOLA ANA NERI}

"Em decorrência das novas relações econômicas e políticas advindas do processo de desenvolvimento urbano-industrial criaram-se as bases institucionais para emergência e absorção de novas forças produtivas, como é o caso da nova classe média" (GRACIANI, 1982). Isto deve-se principalmente ao processo de urbanização que passou a exigir um processo de racionalização do trabalho nas empresas, que visavam fundamentalmente o lucro e a consaeqüente acumulação do capital.

$O$ processo urbano-industrial requeria a existência de um quadro de profissionais técnicos, de supervisores, de administradores etc. e ao mesmo tempo requeria um exército de mão-de-obra semi-qualificada que era constituída basicamente dos ex-trabalhadores manuais. $O$ processo de concentração de renda e propriedade liquidou a possibilidade, antes existente, de pequenos investimentos e poupança. Ao lado dessa situação tinha também a exigência do mercado de trabalho, a necessidade de melhorar as condiçōes de vida e a expectativa de progresso, que muito contribuiram para que em meados dos anos 60 , as chamadas classes médias urbanas desencadeassem movimentos reivindicatórios visando a ampliação e reformulação do sistema universitário, como forma de ascender sócio-conomicamente pelo investimento na educação e para adequá-la à realidade nacional.

"Em vez de levarem adiante os negócios do pai, muitos jovens recebem instruçāo às custas de grandes sacriff́cios para a famflia, que lhes permitirá participar do sistema das grandes empresas que destruiu o pequeno negócio de seu pai"' (GRACIANI, 1982).

Á ordem econômica vigente tendia para uma perda, da antiga classe média, de segurança / estabilidade no que se refere ao poder aquisitivo. Possivelmente isso preocupava bastante as famflias, que temiam um declínio de status tanto financeiro como social. Como não tinham condições de competir no mercado financeiro empresarial, empenhavam esforços e até mesmo sacrificavam-se para investir na instrução dos jovens, como estratégia de manutenção e/ou ascensão da posição social a que pertenciam.

Como vimos, o processo de aceleração urbano-industrial, com todas as suas implicações, motivou ainda mais o movimento reivindicatório no que se refere à Reforma Universitária, principalmente por parte dos estudantes e professores. Este movimento objetivava alcançar melhorias em relação a oportunidades profissionais para os excedentes e também uma reorganização geral da estrutura universitária.

Alguns anos se passaram (ainda na década de 60) nos quais muitas questões foram discutidas, tanto pelo governo quanto pelos professores e principalmente pelos estudantes.

O movimento estudantil pró-reforma contou com a participação de professores, cientistas e outros intelectuais que tinham como unidade de pensamento a atualização do ensino universitário às reais necessidades das diversas regiões do país, o incremento da tecnologia internacional e o progresso da ciência, sem que interesses externos pudessem interferir na orientação das propostas das universidades.

Porém, com a instalação do governo militar em 1964, esses movimentos são pressionados a recuar em nome da organização, da eficácia e da racionalização, que faziam parte da ideologia govemamental. Ainda em 1964, a UNE (União Nacional dos Estadantes) - que foi um forum de debates dos mais importantes e que muito contribuiu para o movimento em prol da Reforma - foi extinta. Em 1968, foi promulgado o Ato Institucional n. 5, que retirou do cidadão brasileiro todas as garantias individuais, públicas ou privadas, assim como concedeu ao Presidente da República plenos poderes para atuar como executivo e legislativo. Em 1969, o Decreto-Lei n. 477, que se aplicava ao corpo docente, discente e administrativo das escolas, coibiu toda e qualquer manifestação de caráter político ou de protesto no âmbito das Universidades, sob pena de suspensão para os estudantes e demissão para os funcionários e professores. Mesmo com o avanço da "repressão" política mediante prisões, torturas, cassações de mandatos e de direitos políticos, inquéritos policial-militares etc., os movimentos em prol de reformas 
sócio-educacionais e de uma política de desenvolvimento mais adequada às reais necessidades da população brasileira continuam a existir. Congressos, reuniões, debates clandestinos são organizados, passeatas que congregam multidões são realizadas, inúmeras greves são deflagradas.

Pelo depoimento de algumas professoras, constata-se que o Diretório Acadêmico da Escola de Enfermagem Ana Neri até 1969, funcionou com muito dinamismo, engajado no movimento estudantil em geral. Porém, no âmbito da Escola não havia comentários sobre os rumos desse movimento nem tão pouco manifestações em prol de reformas.

"Dentro da Escola, o Diretório Acadêmico era algo meio velado.

Em 1969, durante um Congresso clandestino, organizado pela UNE, no interior de São Paulo, a presidente do Diretório Acadêmico de Enfermagem, então aluna da Escola Ana Neri, foi presa juntamente com muitos outros estudantes. Uma contemporânea de Escola dessa aluna faz o seguinte comentário:

" Ela sof ria demais de problemas respiratórios e quando foi presa, a primeira coisa que os danados fizeram foi retirar toda a medicação de que ela precisava. ...sof reu muito, foi tratada como prostituta... Foi libertada com a interferência da diretora da Escola, que foi até São Paulo..."

No mesmo ano, o diretório foi extinto e como muitos outros setores da sociedade, as estudantes de enfermagem ficaram sem forum para os seus debates.

Nesse contexto, foram constiturdos, pelo governo, vários grupos de trabalho para estudar a situação do ensino superior no Brasil e oferecer subsídios para a Reforma. Os relatórios desses grupos inspiraram a elaboração do texto da Lei 5.540/68 que institucionalizou a Reforma Universitária no Brasil.

A questão da "modemização" da Universidade ficou mais por conta do governo, que resolveu bancar a situação, pois descobriu que a inovação poderia ser manipulada sem ameaças à estrutura de poder, ao mesmo tempo em que se ajustaria mais a um certo padrão de desenvolvimento econômico, apontado este aspecto pelas forças internas e externas interessadas nessa modernização, do que por conta dos movimentos de professores e estudantes.

Com a Reforma Universitária de 1968 e as diretrizes dos Pareceres do CFE, o ensino universitário sof reu várias reestruturações e adaptações e não " uma simples revisão de currf́culo ... Havia uma completa mudança de filosofia educacional e do papel da Universidade na formação de lideranças" (OLIVEIRA, 1981).

Ainda por força da Lei 5.540/68, entre outras coisas, ficou estabelecido que os cursos de graduação devem compor-se de: um Ciclo Básico, comum, para áreas afins, objetivando a recuperação de insuficiências evidenciadas pelo concurso vestibular, na formação de alunos; orientação para a escolha da carreira; realização de estudos básicos para ciclos ulteriores e um Ciclo Profissional.

Para a Escola de Enfermagem Ana Neri, algumas das principais transformações ocorridas em decorrência da Reforma foram: - passou a integrar o Centro de Ciências da Saúde/UFRJ; - estudantes do sexo masculino ingressaram nos Cursos; - foi implantada a departamentalização, o sistema de inscrição por disciplinas e o sistema de créditos; foram criados vários órgãos de deliberação com representação discente e de todas as categorias docentes; - as professoras da Escola que acumulavam cargos nos hospitais da Universidade tiveram que optar por um dos cargos. Além disso, a seleção de candidatos passou a ser realizada mediante o vestibular integrado e as disciplinas básicas passaram a ser ministradas no Centro de Ciências da Saúde (CCS). Estes dois últimos fatos af etaram diretamente o poder da Escola de controlar o acesso dos candidatos ao curso de enfermagem bem como o seu processo de iniciação na Universidade.

Vale lembrar que desde a sua criação, em 1923, até o ano de 1971, foi atribuição da Escola Ana Neri a seleção de candidatos ao seu curso. Mesmo ao desvincular-se do Departamento Nacional de Saúde Pública, em 1937, para ser incorporada à então Universidade do Brasil, hoje UFRJ, a Escola manteve essa prerrogativa. Entre os critérios de seleção figurava o de aceitação exclusivamente de candidatos do sexo feminino, além de outros menos objetivos, ligados à aparência, comportamento etc.

Em 1971, registra-se pela primeira vez na história da Escola Ana Neri, a presença de estudantes do sexo masculino em seu curso de graduação.

No entanto, a situação não deixava de atender aos interesses das famflias de candidatas:

"Meu pai deixou eu vir fazer enfermagem porque na Escola Ana Neri só tinha mulheres e porque um Deputado Federal ficou fazendo o papel de meu pai aqui no Rio".

"Era uma garantia para a famnlia, pois só podia entrar mulher ... além disso, tinha o controle do internato para a moça não se perder, mesmo sendo a Escola no RJ' .

Com o advento da reforma e mediante o Decreto n. 68.908 de 13 de julho de 1971, que dispōe sobre o vestibular, essa seleção deixa de ser responsabilidade da Escola e passa para os órgãos de administração acadêmica da UFRJ, instalando-se o sistema de vestibular unificado e classificatório. A partir dar, o sistema de seleção passa a se basear apenas no desempenho dos candidatos em provas objetivas (testes de múltipla escolha). Contemplando inclusive, a possibilidade de aproveitamento dos candidatos não classificados no curso de sua preferência (primeira opção), pelos cursos de menor procura (como o de enfermagem). Isto fez com que as turmas de enfermagem passassem a ser constituídas, em grande parte, por estudantes não vocacionados à profissão 
e muitas vezes apenas esperando ter mais sorte no próximo vestibular. Posteriormente, tentou-se corrigir esta distorção dando preferência aos candidatos de primeira opção para enfermagem, ainda que com número de pontos inferiores aos de segunda opção. No entanto a providência não obteve bons resultados, pois o que ocorreu, foi que os próprios estudantes ao avaliarem suas possibilidades, passaram a preferir se inscrever em um curso que lhes oferecesse mais chances de ingresso (no caso o de enfermagem), embora, na verdade, não desejassem escolher essa carreira. Esses geralmente eram e ainda sāo, aqueles estudantes que por motivos sócio-econômicos não pertenciam a colégios de reputação tradicional e nem puderam frequentar os ' cursinhos' preparatórios de modo a se adestrar para um desempenho superior nos testes de múltipla escolha. Conseqüentemente, os candidatos que ingressavam no curso de enfermagem eram oriundo das classes de menor poder aquisitivo. ras.

Esta situação é assim percebida pelas professo-

"Ainda existem muitos estudantes que vêm fazer enfermagem porque acham que não conseguiriam passar no vestibular de medicina, de odontologia...'

"Acho ótimo quando esses alunos passam no vestibular de outras carręiras' .

Os estudantes confirmam aquela percepção:

" Eu queria mesmo fazer medicina mas como não fiz pré-vestibular pois, minha famúlia não tinha condições financeiras para isso, fiquei com medo de não alcançar os pontos necessários e aí optei pela enfermagem'

Durante o Ciclo Pre-Profissional o único contato desses estudantes com a Escola se dava através de algumas disciplinas ministradas por professores de enfermagem. Esta situação proporcionou ao estudante de enfermagem a oportunidade de convivência tanto com os professores das ciências básicas como como estudantes de outras carreiras da Saúde pois, as disciplinas passaram a ser ministradas em conjunto. Segundo OLIVEIRA (1981), esta aproximação propiciou ao estudante de enfermagem enriquecimento cultural e ampliação de suas expectativas. Outro fato que também contribuiu nesse sentido foi o da extinção do internato da Escola Ana Neri, situado na Avenida Rui Barbosa em Botafogo, passando os estudantes de enfermagem a residir no alojamento da UFRJ, na Cidade Universitária.

Os candidatos aprovados passavam a freqüentar aulas no CCS, ministradas pelos prof essores dos institutos básicos e portanto sem vínculo com a Escola Ana Neri.

Em contrapartida, essa aproximação também é geradora de conflitos:
“ Tinha estudantes de várias áreas (numa reunião) quando chegou minha vez de falar da enfermagem, fiquei envergonhada, pelo preconceito reinante".

A partir de 1978 começou a ser implantado o atual currículo pleno da Escola Ana Neri, no qual se procurou contornar algumas das desvantagens e dificuldades acima mencionadas, como referido na introdução deste trabalho. Não obstante, os problemas continuam a existir. Há descontentamento do alunado principalmente no que se refere às discrepâncias na filosofia educacional e na orientação pedagógica:

"Aqui (na Escola Ana Neri), é diferente do CCS (as professoras) dão mais valor à aparência, ao comportamento do que aos conteúdos teóricos' "Lá no CCS sinto mais liberdade... mas tenho mais medo de ser reprovada".

Na verdade, no início da implantação do atual currículo parece ter havido um retraimento nas reprovações, o que pode ser um reflexo da insegurança das prof essoras de enfermagem em avaliar seus alunos na nova modalidade de ensino:

"Circulou muito tempo, aqui na Escola, o boato que os estudantes não poderiam ser reprovados".

Alguns estudantes demonstram dificuldade em se adptar simultaneamente a duas propostas curriculares: uma projetada em cima de disciplinas isoladas, eminentemente teóricas e teórico-práticas, ministradas com base em livros texto e outras em unidades didáticas integradas, desenvolvidas mediante programas de estudo-trabalho:

" Os estudantes ficam tão obcecados pelas disciplinas do Ciclo Básico que abandonam a proposta de trabalho dos PCIs. Têm pavor de ser reprovados, mas acabam sendo",

Os estudantes parecem ter dificuldades em compreender a proposta curricular da Escola Ana Neri, apesar de insistentemente divulgada e a cada semestre, é freqüente se ouvir do estudante:

" Não conheço os objetivos do PCI e da proposta curricular",

Há também uma reclamação constante de professores e estudantes sobre a inadequação das experiências de ensino-aprendizagem das disciplinas ministradas por professores do CCS, àquelas ministradas pelas professoras de enfermagem.

Mais ainda, há queixas amargas sobre o tratamento dispensado por alguns daqueles professores aos estudantes de enfermagem, que no depoimento desses, chega às raias do desespero:

“Quando o estudante solicita alguma explicação maior, o professor torna-se agressivo e irônico". 
Ouve-se também comentários de que é dentre os professores menos conceituados naqueles institutos que são escalados os que irão ensinar às turmas de enfermagem. Além disso, a freqüênte comparação entre estudantes de enfermagem e outros da área, de carreiras de mais prestígio, sempre desfavorável aos primeiros, neles provoca um sentimento de desvalor característico das situações de discriminação:

"Eles (os professores do Ciclo Básico) dizem assim: quem precisa saber isso é o estudante de medicina, porque ele vai fazer diagnóstico".

"Os professores do CCS acham que nós não precisamos saber muito anatomia, farmacologia... Vêem a enfermagem como uma aprofissão menos importante do que outras da área de saúde".

Parece que o conteúdo das disciplinas básicas, antes da Reforma Universitária, era melhor ministrado e mais adequado à realidade da prática e havia uma melhor relação professor-aluno.

Consta do depoimento de uma professora ex-aluna da Escola Ana Neri:

"No meu tempo, os professores de anatomia, fisiologia... eram convidados pela Escola Ana Neri e demonstravam muito interesse por nós".

\section{CONSIDERAÇŌES FINAIS}

Esta é uma primeira abordagem sobre as diversas situações que podem acarretar dificuldades à integração do estudante de enfermagem na Universidade. Comentários sobre fatos relativos à dinâmica do ensino no curso de graduação e à própria estrutura administrativo-pedagógica da Escola de Enfermagem Ana Neri/UFRJ, facilitam uma melhor compreensão da problemática vivenciada, tanto pelas professoras, como pelos estudantes dessa Escola.

A Reforma Universitária (Lei 5540/68) e o novo currículo pleno do curso de graduação, implantado a partir de 1978, contribuiram efetivamente para que ocorressem mudanças significativas no processo ensino-aprendizagem dessa Escola. Porém, cabe ressaltar que, na percepção de estudantes e professoras, estas mudanças lhes exigiram grandes esforços foram geradas principalmente por:

No caso dos estudantes:

- revisão de seus conceitos e expectativas sobre enfermagem;

- duplo padrão didático-pedagógico CCS/EEAN;

- necessidade de sujeitar-se a um sistema disciplinar, na sua opinião, rigoroso;

- pouca receptividade quanto à sua presença nos órgãos colegiados;

- discriminação por parte dos colegas e professores de outras carreiras da área; sores de outras carreiras da área;

- falta de base de conhecimento.

No caso das professoras:

- perda de controle sobre a seleção e a iniciação do estudante à Universidade;

- necessidade de adotar padrões mais flexíveis e tolerantes em relação ao comportamento social e disciplinar do estudante;

- esforços (frustrados) de articulação com os professores que ministram as disciplinas que compōem o Ciclo Pré-Profissional;

- necessidade de ampliar e aprofundar os ensinamentos teóricos;

- necessidade de adaptar-se à realidade de turmas cuja composição é geralmente mutável devido ao sistema de créditos;

- perda da competência para avaliar devido àinviabilidade do antigo sistema de avaliação na nova situação.

O elenco das dificuldades acima enumeradas , por si só expressa o desconforto de professores e estudantes nesta situação que já dura cerca de quinze anos.

Na perspectiva de uma nova Reforma Universitária, șurge a oportunidade e o dever de participarmos nos debates contribuindo para o aperfeiçoamento da instituição universitária. Para tanto, necessitamos aprofundar nosso entendimento manifestações e seu enraizamento, para podermos pretender criar um espaço de convivência mais proveitosa, em benefício da sociedade.

\section{REFERÊNCIAS BIBLIOGRÁFICAS}

1 BAPTISTA, SS.; PEREIRA, MLM; SAUTHIER, J. O ensino dos conteúdos de Introdução à Ciência da Enfermagem e fundamentos de enfermagem em um currículo integrado - a experiência da EEAN/UFRJ. Revista Brasileira de Enfermagem, Brasilia, 38 (2): 173/9, abr./jun. 1985..

2 CARVAlHO, V. Acerca da mudança do currículo de graduação da Escola de Enf ermagem Ana Neri, UFR - considerações substantivas. 1984. Cópia xerográfica.

3 CARVALHO, V \& CASTRO, I.B. Marco conceitual para o ensino e a pesquisa de Enfermagem fundamental - um ponto de vista. Revista Brasileira de Enfermagem, Brasilia, 38 (1): 76-86, jan./fev./mar. 1985.

4 CASTRO, I.B. A evolução do Setor Saúde e a crise da enfermagem brasileira. 1987. Cópia xerográfica.

5 CASTRO, I.B. et alii. Dificuldades na incoporação dos resultados de pesquisa na prática Enfermagem. In: SEMINÁRIO NACIONAL DE PESQUISA EM ENFERMAGEM 4, Anais... São Paulo, 1985.

6 CONSELHO NACIONAL DE DESENVOLVIMENTO CIENTÍFICO E TECNOLÓGICO. Avaliação e Perspectivas. Brasilia, 1982. 191 p. (Ciências da Saúde, 6 - Enfermagem - 38).

7 Açāo Progranada em Ciência Tecnologia. Saúde e Nutrição. Brasília, 1982. (III PBDCT), 
8 GRACIANI, M.S.S. ensino superior no Brasil - A estrutura de poder na universidade em questão. Petrópolis, Vozes, 1982.

9 OLIVEIRA, M.I.R. O enfermeiro e a Enfermagem. CONGRESSO BRASILEIRO DE ENFERMAGEM, 33, Manaus, ABEn, 1981.

10 OLIVEN, R.G. A Antropologia de grupos urbanos, Petrópo lis, Vozes, 1985.

11 ROMANELLI, O.O. História da Educação no Brasil (1930/1973). 9: ed. Petrópolis, Vozes, 1987.

12 WRIGHT, M.G.M. \& CARNEIRO, A. O espaço da enfermeira brasileira, Revista Brasileira de Enfermagem, Brasilia, 38 (1), 55-62, jan./mar. 1985. 